\title{
The Inclusive Education for Deaf Children in Primary, Secondary and Preparatory Schools in Gondar, Ethiopia
}

\author{
Tadesse Tedla1*; Dawit Negassa ${ }^{2}$ \\ ${ }^{1} \mathrm{PhD}$ Candidate, Haramaya University, Ethiopia; \\ ${ }^{2}$ Assistant Professor, Haramaya University, Ethiopia \\ "Corresponding Author: peace4ujesus@gmail.com
}

\begin{abstract}
The purpose of this study was to investigate the current experiences of deaf children in upper primary, secondary and preparatory schools in Gondar City Administration, Ethiopia. A phenomenological study design with qualitative inquiry approach was used. The main tool used for the study was a semi-structured interview guide, which was developed out of comprehensive review of literature for data collection. Out of the thirty deaf children in the study (26 children from grades 5 to 8 and four children from grades 9 to 12), nine were selected through purposive and available sampling techniques from upper primary, secondary and preparatory schools respectively. The data collected were thematically analyzed though the academic dimension points. Results indicated that the deaf children were not academically included at par with the other students, though they were able to receive support from their peers and were active participants in extra-curricular activities. The deaf children were found suffering from communication barrier, unsuitable and non-varied teaching methodologies and lower expectations on the ability of the deaf children from side of teachers. And, the children were also challenged with the absence of sig language interpreters in their classes and the current text books which they deaf children used to study are lacking the incorporations of adequate pictures. Recommendations such as sign language training for teachers and peers, recruitment of sign language interpreters, acquisition of suitable teaching-learning materials along with adequate training of teachers in using effective and varied methodologies for deaf children have been forwarded.
\end{abstract}

Keywords: academic inclusion; deaf children: upper primary; secondary and preparatory schools

\section{INTRODUCTION}

The Annual Education Statistics Abstract of Ministry of Education (MoE) for 2010/11 showed that the number of children with disabilities who have received education in primary schools in the country was 55,492.This figure indicates that school coverage of students with disabilities (SWDs) is still 3-4 percent of the total population of the group. The rest, 96-97 percent, are still not enrolled in schools. Therefore, it is possible to conclude that the pace of journey of special needs education in Ethiopia is abysmally sluggish (Zelalem, 2014; Tadesse and Lynne, 2015, Aynie, 2016; Alemayehu, 2016).

At present, the favored system for educating
SWDs in Ethiopia is making them attend a special unit school from grades one to four, where specialist skills, including sign language, Braille and mobility are taught. After this point, the students are required to be transferred to mainstream/integrated classes Despite this system of partial inclusion being introduced in 2006, the resources, assistance and accessibility required are still primarily available in urban areas and as such SWDs often need to travel to these areas to gain an inclusive education (UNESCO, 2015; Wilson, 2000 as cited in Anonymous (student number, 150110129), 2016).

Though encouraging track records on the education 
of deaf children have been documented, studies reveal that such children still face a number of challenges at upper primary, secondary and preparatory schools. For example (Alemayehu, 2000; Tadesse and Lynne, 2015, Aynie, 2016; Alemayehu, 2016), in their studies indicated that the status of sign language in Ethiopia is very low, though teachers were caring and accepting. The studies particularly revealed that some of the teachers were professionally unprepared/incompetent, and they lacked sign language competence. Furthermore, many of the sign language interpreters did not have subject matter knowledge and children faced a lot of challenges ranging from social to academics. As a result of the interconnected challenges mentioned; the number of deaf children currently in schools is declining significantly/ dramatically when looked from Kindergarten to higher education institutions (Alemayehu, 2016). Equally worrisome is that there are no sign language interpreters in the country except in the capital city, Addis Ababa (Mulat, Savolaine, Lehtomaki \& Kuorelahti, 2015).

In Addis Ababa and Adama, most of the students without disabilities had a positive attitude towards deaf children whereas their teachers' attitude for the most part was negative (Abebe, 2000). The negative attitude of the teachers could be attributed to the communication and competence problems of these children, thus making it very difficult for their teachers to satisfy their educational needs. However, Asrat (2013) in Bahir Dar City Administration primary schools and Tadesse and Lynne (2015) in North Gondar came up with findings different from Abebe's (2000). They found that teachers had a positive attitude toward the integration of deaf students. But, they depicted the classroom environment and the teaching methodologies unsuitable for helping the academic and physical inclusion of the deaf children. Lately, a study by Berhanie (2017) in Bahir Dar City Administration, revealed that deaf students were not included in physical education.

In Ethiopia, many studies by local and foreign researchers, for example (Deginesh and Asrat, 2016; Mulat, et.al.2016; Mekonnen, Elina and Hannu, 2018; Belay, Fantahun and Missaye, 2015; Nitsuh, 2008) revealed that deaf children's education in the country was of mixed nature having both challenges and opportunities. However, the studies agree that the inclusion of children is less likely to happen in the near future and they recommend bottom up initiative, culturally sensitive, cost effective and community resource based approaches.

Specifically in Gondar City Administration, studies conducted in the area are limited and were only focused on primary schools. Moreover, the available materials were mostly unpublished undergraduate senior essays. Of the published ones, (Tadesse and Lynne, 2015) it was found that in Ethiopia, while the expected age for completing grade 8 was 14; almost all of the deaf students participating in the study were older than 15 and the majority were still in grade 7.

The pressing problem that initiated the present study was the existing scenario that the number of deaf children pursuing their secondary and preparatory education was quite low as revealed from communication made with schools in the study area in particular. Those studies conducted on deaf education in the country for example Abebe, (2000) Alemayehu, (2000), Tadesse and Lynne, (2015), Aynie, (2016) and Belay, Fantahun, and Missaye, (2015) Alemayehu, (2016), Berhanie, (2017), Deginesh and Asrat, (2016), Mulat, et.al. (2016) and Mekonnen, Elina and Hannu, (2018) did not focus on inclusion the larger construct giving focus and weight for either academic, social, and physical dimensions of inclusion, rather all of them tend to study single aspects of inclusion of the deaf children either classroom environment, teachers' attitude, peers' attitude, participation in physical education, communication and or factors affecting the education of the deaf children in general; therefore, the current study is believed to bridge the gap by studying in depth the academic inclusion of the deaf children. What is more, understanding the deaf children's existing academic inclusion opportunities and challenges would serve as an input for future facilitation of full inclusion of deaf children in the country.

\section{RESEARCH QUESTION}

To meet the purpose of the study, the following research question was raised: What is the current situation of inclusive education of deaf children as practiced in primary, secondary and preparatory schools in Gondar City Administration?

\section{OVERVIEW OF ACADEMIC INCLUSION OF DEAF CHILDREN: AN INSIGHT FROM THE LITERATURE \\ Teachers' Expectations of Students' Performance}

Teachers' expectations are essential for the effectiveness of inclusion. Researchers have reported that teachers are more likely to have lower expectations from SWDs than from students without disabilities, and are less likely to uphold accountability for SWDs than for their non- 
disabled classmates Cook (2004) as cited in Roppolo (2016).

However, in the study by Luckner and Muir conducted in U.S, the researchers found that high expectations were a recurring factor in successfully included students (Luckner and Muir, 2001; as cited in as cited in Roppolo, 2016). Indeed, high expectations are important in the education of $\mathrm{D} / \mathrm{HH}$ children because they encourage students to strive to reach their full potential (Roppolo, 2016).

\section{Teachers' Teaching Methodology}

Garguilo (2009) observes that there are no bad students, only poor teachers. He contended that children with hearing impairments learning difficulties may result from having poor teachers who adopt inadequate instructional strategy, implying that the quality of the learning environment contributes to the learning problems faced by this category of students. Research has proven that the academic deficit of the hearing impaired children can be remedied by exposure to individualized and high quality instructional practices adopted by teachers (Garguilo, 2009).

Studies (for example, Berndsen and Luckner, 2012; Cannon, Frederick and Easterbrooks, 2010) support the importance of providing information with visuals. Since visual supports have a big impact and have the ability to enhance students' understanding of instruction. Supporting the instruction with visual aids, such as videos, smart boards, iPads, posters, facial expressions, gestures, body language, and demonstrations, is necessary for students who are deaf and hard-of-hearing (Schultz et al., 2013).

However, different studies from around the world are reporting that the teaching methodologies of teachers of the deaf and hard-of-hearing students are full of problems and as a result, are not addressing the academic inclusion of deaf children. For example, Mapolisa (2013) in his study in Zimbabwe affirmed the assumption that most of the regular teachers lacked the necessary expertise and did not have adequate resources to handle children with hearing impairments.

The majority $(60 \%)$ of deaf and hard-of-hearing students in this study were aware that most of their teachers were not trained for educating students with special needs, and that often their teaching strategies were not very effective when they compared their performance with their teachers in special unit classes (Tadesse and Lynne, 2015). Asrat's (2013) findings indicated that regular classroom teachers' practice in encouraging collaborative learning and involving the deaf students in group task was not good enough to attain the basic objectives of inclusive education. According to Berndsen and Luckner (2010), general education teachers have to be aware that the pace of the instruction and discussions, and quick changes in topics especially challenge students who are hard of hearing and make it difficult for them to access information sufficiently.

\section{Teachers and Interpreters' Communication}

Most mainstream teachers acknowledged that teaching deaf children was difficult for them (for example, Schultz et al., 2013; Berndsen and Luckner, 2010). Some said they were not conversant with appropriate skills and language for teaching deaf students. Large class sizes and inflexible time-tabling also do not allow teachers to pay individualized attention. Such factors often result in attempts to cheat the system as seen in the allegation that certain teachers simply asked the deaf pupils to copy others' work (Musengi and Chireshe, 2012).

Alisam (2018) and Rugg and Donne (2011) in their study indicated that some teachers may not have the knowledge about deafness and the characteristics of the d/Deaf and hard of hearing students. In addition, some teachers may also lack the skills of knowing how to structure classroom activities so as to facilitate the participation and interaction of $\mathrm{d} /$ Deaf and hard of hearing students in the general education classroom.

In Ethiopia, Tadesse and Lynee (2015) highlighted that sign language interpreters were often not actively involved during their lessons in the integrated primary schools, and many $(73.33 \%)$ teachers expressed their frustration with the interpreters' absence. Furthermore, Abebe (2000), Asrat (2013), Deginesh, (2016) and Berhanie (2017) in their study indicated that teachers of the deaf lacked the required training in sign language.

\section{Peer Support}

Peer support involves learners helping one another (Mlay, 2010). It was during their physical education lessons, when playing together, that players who are hard of hearing and their hearing peers started to support one another (Mlay, 2010). Frequently, the hearing peers initiated the interaction by being the referee or by commenting on the hard of hearing actions, but hard of hearing players did it too, when playing in the best way they could (p.62).

Tadesse and Lynne (2015) in North Gondar found that peers of deaf children were found to be quite supportive. The deaf children expressed that they prefer to ask their classmates for help rather than their teachers 
and that their classmates helped them to understand their course materials better. However, the deaf children expressed that they had communication problems with their peers.

There is no doubt that the support given to deaf children by their classmates would make things very easy for them and they prefer it to the support they gain from their teachers and others in the school (Mlay, 2010 and Tadesse and lynne, 2015).

\section{Participation in Extra-curricular Activities}

Co-curricular activities and other recreational programs are also necessary for the growth of a healthy mind and body of Deaf students (Habib, Nadeem, Aslam and te.al, 2011). Their study further indicated that deaf children were participating much less in sports and physical activities as compared to their counterpart students without disabilities.

Tadesse and Lynne (2015) found in their study that deaf and hard-of-hearing children were actively participating in extra-curricular activities. Nevertheless, Mlay (2010) recommend the appropriate offer of physical education to deaf children that it is a subject which facilitates exchange of ideas, togetherness of deaf children with their peers and ensures positive attitude of the non-deaf children towards deaf children.

\section{RESEARCH METHODOLOGY Research Design}

For this research undertaking, phenomenological design, which is hermeneutical phenomenology, was employed. Hermeneutical phenomenology is the study of personal experience and it requires a description or interpretation of the meanings of phenomena experienced by participants in an investigation (Creswell, 2013). According to van Manen (1990) as cited in (Allen, 2013), hermeneutic phenomenological research is a "search for the fullness of living" (p. 12). So in this study the experiences of the deaf children in their social, academic and physical inclusions has been thoroughly covered and analyzed and finally evidence based interpretation, meaning and analysis were made using previous studies nationally and internationally.

\section{Sampling Technique}

In Gondar City Administration, there are 46 primary schools, five secondary schools and four preparatory schools referred to as public schools totaling 55. Deaf students can receive inclusive education in these schools.
One primary school (Tsadiqu Yonannes), one high school (Ayer Tena) and three preparatory schools (Hidar 11, Debreselam and Fasiledes), totaling five schools were selected for this study through available sampling technique. The only justification for selecting these schools was that, at the time of the current study, deaf children were found only in the above-mentioned public schools in the city. All the deaf children were medically certified on their deafness.

Hence, from Tsadiqu Yohannes primary school from amongst 26 deaf children (in grade $5=5$ deaf children; in grade $6=8$ deaf children; in grade $7=7$ deaf children and in grade $8=6$ deaf children) two from grade eight and one from each grade, totaling five deaf children were selected. From Ayer Tena high school (in grade nine, one deaf child), from Hidar 11 preparatory school (in grade eleven, one deaf child), from Debreselam preparatory school (in grade eleven, one deaf child) and from Fasiledes preparatory school (in grade twelve, one deaf child) totaling four deaf children were selected. Hence, nine deaf children were selected for this study ( 7 females and 2 males).

\section{Data Collection Instrument}

The most appropriate data collection strategy for a phenomenological research is interview with open or semi-structured questions to investigate things in detailed manner. These two types of interviews allow the researcher to address the phenomenon profoundly, providing a space of opportunity for the informants to express their experiences in detail, approaching reality as faithfully as possible. The detailed descriptions or interpretations brought by the participants in the profoundphenomenological interview should be as representative of experienced reality as possible (Padilla-Díaz, 2015, p. 104)

Semi-structured interview guide was developed by the researchers after comprehensive review of related literature on academic inclusion. The developed instrument was validated by two teachers in special needs education who are working in special unit of Tsadiqu Yohannes primary school which was one sample school of this study. These two teachers were also data collectors at the same time.

\section{Ethical Considerations}

First of all, informed consent of the probable participants for this study was sought. Participants were informed that the information provided by them will remain confidential and will be used for academic purposes only. Sign 
language interpreters were recruited for data collection and they played the role of receiving consent agreement and ensuring confidentiality. In the end, data presentation and analysis were made based on the available data from respondents.

\section{Data Collection Procedures}

The following procedures were used while collecting data; letter of permission from the department of SNIE of University of Gondar was obtained and was given to the schools' principals; two data collectors who had faultless sign language skills were recruited in consultation with the principal of Special Unit of Tsadiqu Yohannes primary school. In the school, special needs education professionals were available in large numbers as the school is the only inclusive school in the city. The two data collectors were female teachers with ample experience of working with the deaf children. Both were graduates in special needs with valid certificates from Sebeta and Debre Birhan. Currently, both are pursuing their masters and bachelors degree in special needs education at University of Gondar in summer program; through the help of the recruited two professional teachers, the objective of the research was explained to deaf children and respondents were selected and consent of agreement was acquired; good rapport was established with willing respondents through the support of the recruited teachers; respondents were interviewed in their schools. During the interview sessions, while one teacher was interviewing a deaf child, the other teacher would make a mobile video record of the session. Almost, each interview took a maximum of 40 minutes; the data collection and the translation started from December 11 and ended on December 24. The researcher then translated the text from Amharic to English language with maximum accuracy. Subsequently, results and discussion were presented based on the available data.

\section{Methods of Data Analysis}

Colazzi's (1978, 48-71), cited in Schuemann (2014), describes a phenomenology data analysis model that highlights conceptual patterns any researcher in phenomenological research must follow in the analysis phase. Hence, the data analysis in this research was guided by the guideline of Colazzi's (1978, 48-71) seven steps.

Before anything else, the researcher thoroughly read the transcribed interviews to become familiar with the data and to acquire a sense of each individual's experiences; from the transcripts the researcher identified significant statements which pertain directly to noteworthy phenomena. The researcher then tried to develop interpretive meanings of each of the significant statements. Furthermore, the researcher reread the research protocol to ensure the original description is clearly reflected in the interpretive meanings. The interpretive meanings were subsequently arranged into clusters, which allowed themes to emerge; the researcher sought validation, avoided repetitive themes, and noted the discrepancies during this process. The themes were then integrated into an exhaustive description. The researcher also referred the theme clusters back to the protocols to substantiate them. Afterwards, the researcher produced a concise statement of the exhaustive description and provided a fundamental statement of identification also referred to as the overall essence of the experience. The shortened statement of the exhaustive description was presented to the study's participants in order to verify the conclusions and the development of the essence statement and to note if any discrepancies were identified.

\section{RESULTS AND DISCUSSION}

The results and discussions are presented in a way to provide answers to the research question raised in the beginning of the study. The first question about the academic inclusion of the deaf children (concerned about the deaf children's experience on areas of teachers' expectations of student's performance, teachers' teaching methodologies, teachers and interpreters' communication skills, peer support and participation in extra-curricular activities). In presenting the cases, to keep confidentiality, the principle of anonymity was maintained. In doing so, as there were nine cases, each case was given a number based on the grade level of the participant. Hence, here after, we will have case 5 , case 6 , case 7 , case $8 \mathrm{~A}$, case $8 \mathrm{~B}$, case 9, case $11 \mathrm{~A}$, case $11 \mathrm{~B}$ and Case 12 for respondents from grade five, six, seven, eight, nine, eleven and twelve respectively.

\section{Academic Inclusion of the Deaf Children \\ Teachers' Expectations of the Deaf children's Performance}

The deaf children were asked, "Do your teachers believe in your academic potential?" Most of the respondents replied no. Teacher expectations are essential for the effectiveness of inclusion. As was explained before, teachers are more likely to have lower expectations from SWDs than from students without disabilities, and are less likely to uphold accountability for SWDs than for their non-disabled students Cook (2004) as cited in Roppolo (2016). The current study came up with a finding which is 
consistent with Cook's (2004) finding as cited in Roppolo (2016) that the teachers' expectations on the academic potential of deaf children was very low.

The low level of expectation of children's performance by teachers has resulted from intertwined factors as reported by the deaf children. The first one is, the deaf children perform less and participate less in group project works due to communication barrier. As a result, they achieve less in their academic performance which in turn serves as evidence for teachers. Consequently, teachers maintain low expectations of the deaf children. We understand this from what case 5 revealed;

Taking into consideration the teaching learning process that I do not participate and judgment based on assessment results from continuous and summative assessments that my achievement is low my teachers think I cannot bring any changes in my grades. Thus, their confidence in me is low.

Case 6 indicated that the problem will remain forever unless she recovers her hearing again or the school community learns the sign language. She said;

My teachers take only my low achievement in exams and my low participation in class activities and do not think I can bring a change in my grades. The teachers will continue their disbelief and undermining my potential unless my language problem is resolved.

The second challenge is that the attention that is paid to deaf students, though encouraging, is not adequate and the teachers are aware of this fact. So they are desperate and are keeping their disbelief. The following is what was said by case 7 :

Many teachers know I have language problem and have already perceived that as a result, my participation is low. They do not think I could progress like other students. Because they doubt the fact that less attention is paid to deaf students by different stakeholders.

The third challenge is, the assessment modality which is achievement oriented results in lower performance records of the deaf children, thus reinforcing teachers' skepticism of the potential of the deaf children. Case 11B depicted the scenario in the following words;

Teachers doubt my academic potential. I do not understand what teachers teach in their subjects due to language barrier. Consequently, I have a record of low achievement in continuous and summative assessments. So teachers doubt my potential not only today, but also doubt about my future fate too.

In a nut shell, the deaf children expressed their fear that the mistrust of their teachers would continue in the future as well unless sign language interpreters were made available in the classrooms now. Case 8A came up with the following narration;

Teachers think unless sign language interpreters are recruited, we [deaf children] will never finish our high school education and will never be successful in our life in the future too.

Case $8 \mathrm{~B}$, further supported what was explained by case $8 \mathrm{~A}$ in the passage cited above with the conviction that, "had they been taught with the assistance of interpreters, they could have been competing and achieving better". She affirmed that;

...had we had interpreters we could have been competitive equally with the hearing ones and could be judged by our results.

In Ethiopia, Tadesse and Lynee (2015) depicted that sign language interpreters are not involved during lessons in class of the deaf children in the integrated primary schools, and many of the deaf children $(73.33 \%)$ expressed frustration due to their absence. Furthermore, Abebe (2000), Asrat (2013), Deginesh, (2016) and Berhanie (2017) in their study indicated that teachers of the deaf lacked the required training in the area and as a result were unable to meet and satisfy the needs and interests of deaf children, making the inclusion process an uphill battle.

There is very little evidence available concerning sign language interpretation and its effect in Ethiopia (Alemayehu, 2016). Furthermore, observers have found that in many cases, interpreters are ineffective because they lack the content knowledge, pedagogical skills and Standard English language proficiency needed for preparatory grades. Alemayehu (2016, p.112) reported that in Addis Ababa, the capital city of Ethiopia, the education level of interpreters' working in government public schools was insufficient for them to understand the contents of preparatory school subjects. The worst is, in schools such as in the current study, interpreters are not available at all. 


\section{Teachers' Teaching Methodologies}

The deaf children were asked, "Are your teachers' teaching methodologies suitable to satisfy your learning needs? Do they use varieties of teaching methodologies?" Almost all the respondents gave a response of "No." The teachers' teaching methodologies are not suitable to their learning needs; as a result almost all the children are not satisfied. For example, case 9 openly stated that;

I have never got suitable teaching methodologies so far. I used to understand and communicate when I learnt by special unit teachers [she is referring to her 1 to 4 grade teachers]. Now the teachers never use any different methodology for me. Teachers do not have any suitable methodology for me and I am therefore unhappy.

Case $11 \mathrm{~A}$ added an overview of how all the teachers follow the same fashion and techniques and, therefore, their teaching is not benefiting deaf students;

The teaching methodologies that teachers often use are not helping me much; because teachers' methodologies are not helping me to get good academic achievement and equal participation like hearing ones. Often, teachers' teaching methodologies are not different; they use group work and home work all the time.

However, there was one respondent (case 5) who stated that when teachers use pictorial aids as one component of the teaching methodology, lessons become clear;

Teachers use student-centered methodology that I do not participate in because it is not suitable for me. Often I participate only in note taking and in HPE period outside the classroom. Teachers do not teach using methodologies suitable for deaf students. But, very few teachers, for example geography teacher, use pictures that help me to better understand the subject.

The above finding is consistent with studies which confirmed for example (Berndsen and Luckner, 2012; Cannon, Frederick, and Easterbrooks, 2010) the importance of providing information with visuals.

The unsuitability of the teachers' methodologies was further complicated with the addition of communication barrier and hence the respondents eagerly expressed that they needed special education needs professionals in their classes as had been so in their lower classes. Case 8A openly stated;
Whatsoever methodologies teachers use will not be effective unless communication barriers are removed. I do not mean to condemn my teachers because they do not realize that I cannot follow their language. I think the education system will be suitable for me if I am taught by special needs education teachers up to grade 12 .

The above narration is consistent with the findings of Tadesse and Lynnes' (2015) that indicated the majority $(60 \%)$ of deaf and hard-of-hearing students in their study were aware that most of their teachers were not trained for educating students with special needs. Often teachers' teaching strategies were not very effective when compared with teachers in special unit classes. Consistent also with Asrat's (2013) finding that indicated regular classroom teachers' practice in encouraging collaborative learning and involving the deaf children in group task was not effective enough to achieve the basic objectives of inclusive education.

\section{Teachers' and Interpreters' Communication}

The deaf children were asked, "Is it clear and understandable to you the language that your teachers and interpreters use?" All of the respondent students replied that there were no interpreters and the language their teachers used was not clear and understandable. Their teachers use only body language and they sometimes communicate in writings. As a result of it, things are too complicated. For example; the following narration by case 7 is a good illustration of this phenomenon;

Teachers teach in presentation methodology that I cannot listen to. Hence, lessons are not clear for me. I understand quite a little when teachers bring multiple choice questions and when they communicate through writing. Many times, I want to understand the subjects I learn but I cannot. That is why I do tests and exams by just guessing the answers.

Lessons become less complicated when their teachers use teaching aids. In addition to this, the respondents frequently aspired to have interpreters throughout the interview sessions. Case 6 for example said;

The teachers' language is not clear for me as they cannot use sign language. I somewhat understand lessons when the teachers use pictures and other teaching materials. We do not have interpreters in our school. In the future, if I am lucky enough to 
get an interpreter in our school, my problems will be solved and I can express my opinions so that I can understand my lessons better.

The deaf children, due to the unavailability of sign language interpreters on the side of their teachers, when they have difficulties understanding their teachers, they seek the support of their ex-special unit teachers. Case 8B said;

...usually when we get problems with teachers and are unable to communicate about it, special unit teachers will be called upon and then I can convey my feelings/issues to them. Then we feel happy and our problems get resolved...

The above finding is consistent with international findings (for example, Musengi and Chireshe, 2012; Alasim, 2018; Rugg and Donne, 2011) who concluded, most mainstream teachers acknowledged that teaching deaf children was difficult for them. Some said they were not conversant with appropriate skills and language for use.

Furthermore, the findings are also consistent with local findings. For example, Tadesse and Lynee (2015) depicted that sign language interpreters are not involved during lessons in the integrated primary schools and many of the deaf children $(73.33 \%)$ expressed frustration due to their absence. Also, Abebe (2000), Asrat (2013), Deginesh, (2016) and Berhanie (2017) in their study indicated that teachers of the deaf lacked the required training in the area and as a result were unable to meet the needs and interests of deaf children, making the inclusion process challenging.

\section{Peer Support}

The deaf children were asked, "Do your peers support you in your education? In what ways do they support you?" Almost all the respondents happily replied that their peers support them in many ways. It is a consistent finding with Tadesse and Lynne's (2015) findings. They depicted that peers of deaf children were found to be quite supportive. For example, case 5 came up with detailed explanation of the assistance she receives from her classmates;

My classmates try to support me in the teachinglearning process. For example, they allow me to copy homework questions and show me class work activities. They share with me points that they speculate will appear in exams through hand sings. They help me with those questions and we are given good marks for group work.

The results of the current study were consistent with the findings of Mlay (2010) that indicated it was during their physical education lessons when playing together that deaf learners and their hearing peers supported one another. Case 9 narrated that;

...more than any other time, my classmates and I are happy when we play together in the sport fields. While doing the sport activities, we talk about lots of things and have a lot of fun, greater understanding and togetherness.

The study came up with consistent finding that confirmed classmates and peers give supportive assistances to deaf children more than teachers and other community members in the school; for example Mlay (2010) and Tadesse and Lynne (2015). However, there seemed to be a problem with the support of peers to the deaf children in this study. Most of the deaf children expressed that their peers do their assignments under the shoes of the deaf children. The deaf children submit assignments as if they did their assignments by themselves while they are not. So it seems the deaf children are not standing in their feet's and they are arguably dependent on their classmates. It was clear in what case 5 at the end said in the above. Case 7 on his part honestly stated that;

The support that I receive from my classmates in and outside the class is most of the time when we are given homework and class work to do, they do it for me as I do not understand the lessons properly. When we are given group work, they do it as if I were also part of the engagement. They do this not because I ask them, but because they sympathize with me.

Case $11 \mathrm{~A}$ added that;

My classmates were more than willing to help me with my education if only we could communicate through language. Thus, for supporting me, they write my notes, they show me what they did when homeworks are given. when we are given project works they do it at their homes and deliver it to me.

Nevertheless, even though the support of peers has always been available, the interaction is often challenged by language barrier as can be easily understood from the reports of the cases consistent with the findings of this study as indicated in previous studies, for example Tadesse and Lynne (2015).

\section{Participation in Extra-curricular Activities}

The deaf children were asked, "Do you participate in different extra-curricular activities? For example, in sports and mini-media? Except for Mini-media, the 
deaf children expressed that they happily participate in extra-curricular activities such as, music, dance, running, jumping, volley ball, students with disabilities club, etc. Especially they loved their sport class or sport clubs. The finding is contradictory with what Habib, Nadeem, Aslam and et.als' (2011) study that indicated deaf children were less participating compared to their counterpart students without disabilities in sports, co-curricular and other physical activities. Rather the results were complementing the findings of Tadesse and lynne's (2015) that indicated deaf and hard-of-hearing children expressed their joy at participating in extra-curricular activities. That is why, Mlay (2010) recommended a call for the recognition of learners who are hard of hearing in physical education, which is among of the most interactive subjects and easy for the learners to express their feelings and behaviors. This could enhance modification and help them to improve their relationship with their peers, particularly in regular schools. It is also a source of happiness and it opens a room for the deaf children to participate in Para-Olympic games. A Gold medal was won by Case 6 with her associates;

There is a sport club in the school in which I also participate. Most of the time I participate in Para-Olympic competitions starting from Woreda to Kilil (district to Regional). I am happy that I participate in the competition. Last year, 2010 E.C [2018, GC] for example, we have brought gold medal in women's competition at Regional level. I know there is mini-media in the school, other students in lining (flag ceremony) and break time they deliver poems and convey different messages; but I do not participate.

The most rousing factor for the respondents to participate in extra-curricular activities was the support and encouragement they receive from their teachers. Case 9 narrated this interesting support in a glowing tone;

... My HPE teacher always appreciates my participation and supports me to continue.

Above all, another encouraging finding was that the respondents were active members of disability clubs and special unit teachers kept up their supports. Case 7 expressed his engagement in disability and charity clubs and the continued support of special unit teachers in this regard.

Special unit teachers have selected me to participate in disability and charity clubs, I participate in song and dance. The teachers have explained to me the objectives of the clubs through sign langue that is why I am always happy to engage myself in the clubs. But, I don't participate in mini-media clubs.

\section{CONCLUSION AND RECOMMENDATION Conclusions}

The deaf children were found to be less included academically. In fact, the deaf children were lucky enough to be able to receive good support from their peers and actively participate in extra-curricular activities such as in music, dancing, running, jumping, volleyball and charity and disability clubs. However, when the academic inclusion of the deaf children is evaluated in major parameters of teachers' expectation on the respondents' potential in academic performance, teachers' teaching methodologies and teachers' and interpreters' communication, it was found questionable. Though respondents witnessed that they have lower participation and achievement due to various reasons such as achievement oriented assessment mechanism and lower attention paid to them by the stakeholders and the like; the teachers hold exaggerated lower expectation on the potential of the deaf children to the extent of doubting the future achievements of these children and they disbelieve their success in life. The teachers' teaching methodologies were found to be common to all students involving group work, class work and project work and with little or no pictorial presentations. Added with communication barrier between the two actors, this in turn left the teaching methodologies unresponsive to the respondents learning needs. In addition to this, interpreters were not available in the class which worsened the communication barrier between the children and their teachers. This then forced them to communicate through body language and writing which, as witnessed by respondents, is a great predicament making the academic inclusion of the respondents always unsatisfactory.

\section{Recommendation}

Gondar City administration educational office and the school principals need to work together to make teachers, students and significant school communities to be able to have sign language skills through short and long term trainings and if possible adequate number of sign language interpreters need to be recruited.

\section{REFERENCES}

Abebe, G. (2000). Attitude of teachers and students regarding 
the integration of hearing impaired students into regular classes. Masters Thesis, Addis Ababa University, Addis Ababa, Ethiopia.

Alasim, K. (2018). Participation and Interaction of deaf and hard-of-hearing students in inclusion classroom. International Journal of Special Education, 33(2), 493-506.

Alemayehu, T. (2000). Sign language: Basic concepts and its structure. Education Journal, 4(10), 44-70.

Alemayehu, T. (2016). Quality of interpretation services and its implications in creating inclusive classrooms for deaf preparatory school students. Eastern Africa Social Science. Research Review, 32(2), 103-122.

Allen, K. (2013). A hermeneutic phenomenological study of the lived experiences of individuals in intercultural relationships. Masters Thesis, University of Regina, Regina, Canada.

Anonymous (Student number, 150110129). (2016). Inclusive education for students with visual, hearing and physical disabilities: barriers and experiences in Gondar, Northern Ethiopia. Masters Thesis, University of Sheffield, Sheffield, United Kingdom.

Asrat, D. (2013). Factors affecting the implementation of inclusive education in primary schools of Bahir Dar Town Administration. Education Research Journal, 3(3), 59-67.

Aynie, B. (2016). Practices of special needs education teachers in teaching sign language to deaf students the case of North Showa Zone of Amhara Region. Masters Thesis, Addis Ababa University, Addis Ababa, Ethiopia.

Belay, T. Fantahun, A. and Missaye, M. (2015). Education of children with special needs in Ethiopia: Analysis of the rhetoric of 'Education ForAll' and the reality on the ground. The Ethiopian Journal of Education, $X X X V(\mathrm{I}), 45-97$.

Berhanie, A. (2017). Challenges and experiences on inclusive physical education: The case of Bahir Dar elementary schools. International Journal of Physical Education, Sports and Health, 4(2), 94-99.

Berndsen, M., \& Luckner, J. (2012). Supporting Students Who Are Deaf or Hard of Hearing in General Education Classrooms: A Washington State Case Study. Communication Disorders Quarterly, 33(2), 111-118.

Cannon, J. E., Fredrick, L. D., \& Easterbrooks, S. R. (2010). Vocabulary Instruction Through Books Read in American Sign Language for English-Language Learners With Hearing Loss. Communication Disorders Quarterly, 31(2), 98-112.

Creswell, J.W. (2013). Qualitative Inquiry \& Research Design: Choosing among Five Approaches. Los Angeles, CA: Sage.

Deginesh, D. and Asrat, W. (2016). Review of challenges of hearing impaired students in integrated class in public schools in Ethiopia: A review article. Journal of Medicine, Phsiology and Biophysics, 1(22), 74-78.

Garguilo, R. M. (2009). Special education in the contemporary society: An introduction to exceptionality (3rd ed.). Los Angeles: SAGE.

Habib, M. Nadeem, M. Aslam, H. Ahmad, M. and Hussain, Z. (2011). Assessing the importance of co-curricular activities in special people (Deaf) learning at elementary level. International Journal of Business and Social Science, 2(11), 165-172.

Mapolisa, T. (2013). The impact of inclusion of children with hearing impairment into regular schools: A case study of Dakamela primary school in Zimbabwe. International Journal of Asian Social Science, 3(7), 1500-1510.

Maxwell, J. A. (2005). Qualitative research design: An interactive approach (2nd ed.). Thousand Oaks, CA: SAGE

Mekonnen, M. Elina, L. and Hannu, S. (2018). Academic achievement and self-concept of deaf and hard-ofhearing and hearing students transitioning from the first to second cycle of primary school in Ethiopia. International Journal of Inclusive Education, -(-), $1-15$.

Ministry of Labor and Social Affairs (2010). Baseline study on the status of persons with disabilities and the influence of the Africa decade pronouncement in Ethiopia. Policies and program implementation. Final Report. Commissioned by the Secretariat of the African Decade of Persons with Disabilities.

Mlay, J. (2010). Interaction between learners who are hard of hearing and their hearing peers in physical education lessons: A case study of learners who are hard of hearing in physical education, Tanzania. Masters Thesis, University of Oslo, Oslo, Norway.

Mulat, M. Savolaine, H., Lehtomaki, E. and Kuorelahti, M. (2015). Socio-emotional problems experienced by deaf and hard-of-hearing students in Ethiopia. Deafness and Education International, 1(17), 155162 .

Mulat, M. Savolaine, H., Lehtomaki, E. and Kuorelahti, M. (2016). The self-concept of deaf/hard-of-hearing and hearing students. Journal of Deaf Studies and Deaf Education, 21(4), 345-351.

Musengi, M. and Chireshe, R. (2012). Inclusion of deaf students in mainstream rural primary schools in Zombabwe: Challenges and opportunities. Stud Tribes Tribals, 10(2), 107-116.

Padilla-Díaz, M. (2015). Phenomenology in educational qualitative research: Philosophy as science or philosophical science? International Journal of Educational Excellence, 1(2), 101-110.

Roppolo, R. (2016). The perceptions of general education 
teachers on the inclusion of students who are deaf or hard of hearing in the general education classroom. Bachelor Thesis, The University of Southern Mississipi, Mississippi, United States of America.

Rugg, N. and Donne, V. (2011). Parent and teacher perceptions of transitioning students from a listening and spoken language school to the general education setting. The Volta Review, 111(3), 325-351.

Schuemann, K. (2014). A phenomenological study into how students experience and understand the university presidency. Doctoral Dissertation, Western Michigan University, Michigan, United States of America.

Schultz, J. L., Lieberman, L. J., Ellis, M. K., \& Hilgenbrinck,
L. C. (2013). Ensuring The Success Of Deaf Students in Inclusive Physical Education. JOPERD: The Journal of Physical Education, Recreation \& Dance, 84(5), 51-56.

Tadesse, A., and Lynne S. (2015). An assessment of factors affecting the education/inclusion of deaf and hardof-hearing students in North and South Gondar Zone integrated primary school classes. Ethiopian Renaissance Journal of Social Sciences and the Humanities, 2(2), 37-53.

Zelalem, T. (2014). The journey of special needs education in Ethiopia: An overview. Journal of Education and Practice, 5(27), 83-85. 